\title{
The Protecting Challenges of a Distributed Generation Unit Connection to Medium Pressure Feeder
}

\author{
Milad Ashouri ${ }^{1}$, Kazem Ameli ${ }^{2}$ \\ ${ }^{I} M S c$ student of Electrical Department, Torbat-E-Heydarieh Branch, Islmic Azad University، Torbat-E- \\ Heydarieh, Iran \\ ${ }^{2}$ Department of Electrical, Torbat-E-Heydarieh Branch, Islmic Azad University، Torbat-E-Heydarieh, Iran
}

\begin{abstract}
Using the Distributed Generation production resource and small ones, especially the renewable energies are the strategic aim of electricity part of power ministry. The benefits such as reduction of net loss and environment pollution, in addition to fossil fuel consumption saving and variety in energy conversion resources are the main reasons that government protects the small and distributed producers. Considering the classic power distribution systems, the protection of safe extraction, net stability, short conjugation surface, net islanding, unsuitable control in production volume and its control are the problems that exist against of these units conjugation to the distribution network. A gas unit conjugation to the power distribution network, regarding the protection and coordination problem, is one of the issues that has been studied in this article.
\end{abstract}

Keywords: Distributed Generation, Protection Challenge, Relay, Power Distribution Network.

\section{Introduction}

Electrical networks reliability increasing will be made when the effects of these units entering to the distribution system considered and their flaws be eliminated. One of the most important issues against of scattered unit's linkage to the distribution networks is the protecting challenges studies. The classic radial nature of distribution networks will be disappeared in consequence of scattered production units. Therefore at first is essential to evaluate the network situation and location of production units in protection performance viewpoint of classic distribution network systems. The complexity of subject is higher when the aforementioned units don't be in circuit and the network changes to radial form again. Some troubles are as below:

KV 20 feeder unnecessary exit

Unseasonable exit of scattered production units

Increase or decrease of network short linkage

Unwanted islanding

Protection systems blinding

Production unit exit and generation of new situations

All upper factors will cause the more attention of protection systems of distribution network. The DG effectiveness amount on coordinated protection depends on size, type and its location. Depend on size and locations there are some areas that coordination keeps and on the other situations there is no coordination at all.

\section{Study Method}

This article showed the topography of DG unit linkage to the network, the condition of production unit linkage in protection challenges viewpoint and the network improvement situation assessment using the DLGSILENT software. Finally some suggestions have been presented about the novel adjustment for protection systems.

\section{Network topology introduction}

The industrial Estates logically should be supported via an independent and isolated power providing units, considering their related process sensitivity and lack of reliability to the public network. Since the present study focuses on protection systems, therefore the main problems of classic systems for new situations are as below:

- The condition and way of distribution network and DG unit land and consequently the system situations in single phase error to the earth.

- The situations of distribution network land to the industrial Estate, DG unit and protection system overview based on network with double side feeding. 


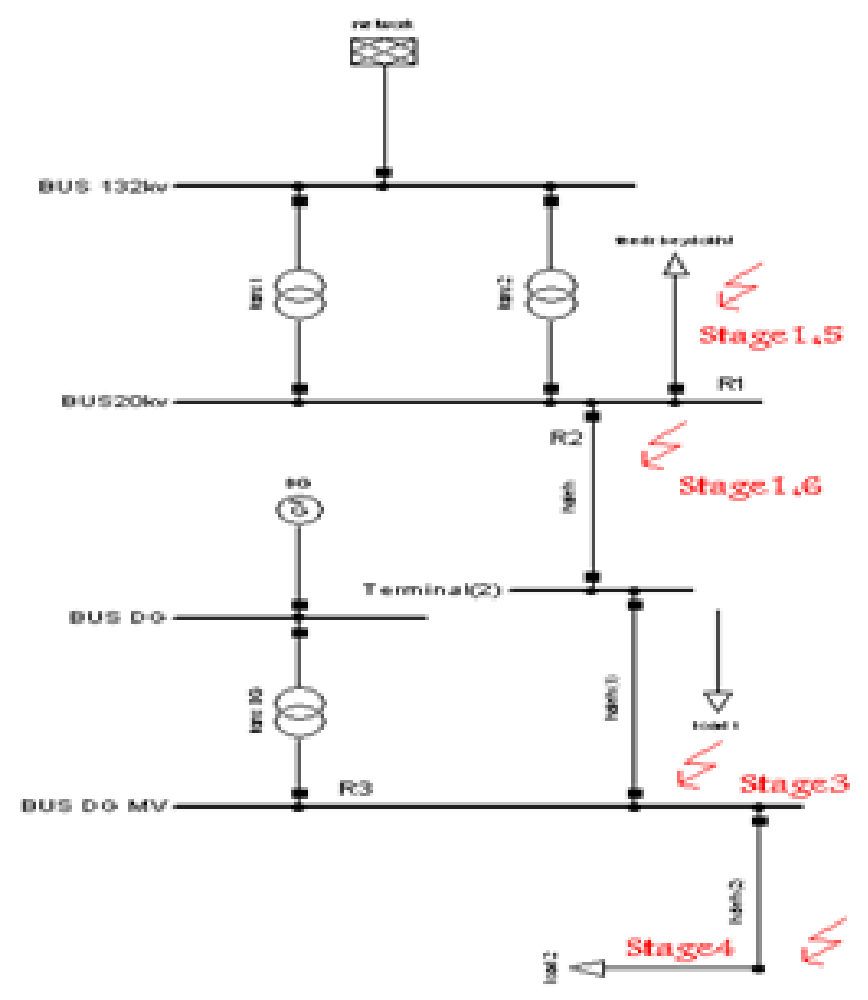

Fig1. Power plant diagram and the way of network linkage

Figure 1 shows the way of aforementioned units to the network in a simple schematic diagram. Despite the anticipated benefits the unit protection, the feeder and post relay setting have been put the challenges against the extractors. The network analyze in flaw situations is one of the necessities of distribution network studies. The results can be used for below targets.

- Keeping the stability and reliability of network in linkage of scattered production units at error occurrence time.

- $\quad$ Keeping in circuit the DG sources when the flaw occurs in distribution networks.

- $\quad$ Keeping in circuit the DG sources in renewed connection.

\section{Protection devices of $20 \mathrm{KW}$ feeders in upper distribution post and DG unit}

In distribution systems the protection devices limited in Fuses, Overcurrent Relays, earth connected relays, sequencers and keys. Figure 1 shows the one linear diagram of study network. The protection devices in $20 \mathrm{KV}$ in this post on exit feeders are Overcurrent Relays and earth connected relays. These relays activated when the transferred current over a distinct part increases more than given amunt, these relays equiped with type curve of inverse time and have below function:

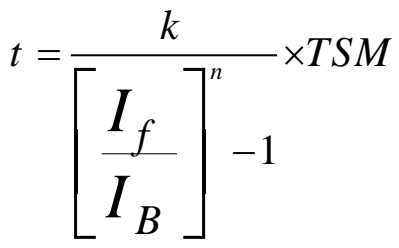

IB :base current setting

If : inputed current to relay

T.S.M :time setting coefficient

Table1. Current relay properties

\begin{tabular}{|l|l|l|}
\hline $\mathrm{K}$ & $\mathrm{N}$ & CHARACTERISTIC CURVE \\
\hline 0.14 & 0.02 & NORMAL \\
\hline 13.5 & 1 & REVERSE \\
\hline 80 & 2 & VERY REVERSE \\
\hline 120 & 1 & LONG REVERSE \\
\hline
\end{tabular}




\section{Evaluation of DG Earth connection system}

For the assessment of DG earth connection way, the different situations for various states have been analyzed via the software contain the transformer star point connection and DG generators consists of isolation, direct connection and connection via resistor. Results have been presented in table 2 briefly.

Table2. Results of earth connection study

\begin{tabular}{|l|l|}
\hline \multicolumn{2}{|l|}{ THE RESULTS OF THE STUDY OF THE EARTH SYSTEM } \\
\hline $\begin{array}{l}\text { SHORT CIRCUIT CURRENT AT } \\
\text { THE CONNECTION POINT }\end{array}$ & THE STUDY STATES \\
\hline 58 & $\begin{array}{l}\text { ISOLATED GENERATOR AND TRANSFORMER } \\
\text { DIRECTLY GROUND }\end{array}$ \\
\hline 0.5 & $\begin{array}{l}\text { ISOLATED GENERATOR AND TRANSFORMER BY } \\
\text { HALF OHM RESISTANCE }\end{array}$ \\
\hline 1 & $\begin{array}{l}\text { GENERATOR AND TRANSFORMER EACH BY HALF } \\
\text { OHM RESISTANCE EARTH }\end{array}$ \\
\hline 39.71 & $\begin{array}{l}\text { GENERATOR DIRECTLY AND TRANSFORMERS BY } \\
\text { HALF OHM GROUND RESISTANCE }\end{array}$ \\
\hline 58 & TRANSFORMERS DIRECTLY AND GENERATOR BY \\
& HALF OHM GROUND RESISTANCE \\
\hline 60.78 & TRANSFORMER AND GENERATOR DIRECTLY \\
& GROUND \\
\hline
\end{tabular}

As it can be seen in table 2, the best condition of DG earth connection condition is the generator isolation and unit transistor linkage by the $0.5 \mathrm{ohm}$ resistor to the earth. The system situation in presence of scattered production with triple and single phase connection have been evaluated with DIgSILENT software modelling.

\section{Error analyze in network}

The presence of DG on feeder means that different resources for error feeding has been occurred and the relay performance of overcurrent will be stopped. These problems are not justified in economic and technical sides and reduces the reliability. Assessing the various states in DG input the different connection situations in study network of figure 1 has been simulated. The connection situations have been presented in table 3 for 6 state. For simulation results surveying the performance time of breakers has been considered 6 cycle. For short connection calculations the IEC60909 standard. Based on catalog for selected DG, the based setting current has been considered equal to 85 .

Table3. Different situations of short connection of DG to the network based on fig1

\begin{tabular}{|l|l|l|}
\hline ERROR TYPE & ERROR LOCATION & STATE \\
\hline 3-PHASE EARTH & ADJACENT FEEDER & 1 \\
\hline 3-PHASE EARTH & THE BEGINING OF THE HALE FEEDER & 2 \\
\hline 3-PHASE EARTH & DG BUS CONNECTION IN THE HALE FEEDER & 3 \\
\hline 3-PHASE EARTH & ALONG THE HALE FEEDER AFTER CONNECTING & 4 \\
\hline 1-PHASE EARTH & ADJACENT FEEDER & 5 \\
\hline
\end{tabular}

State1. Results show the 11.74 Kamp crossing current from adjacent feeder and 0.159 Kamp crossing the DG relay. Based on protection philosophy the adjacent relay performed sooner and the protection system will perform justified. It can be resulted that because of short triple phase connection in other feeders the protection balance will not be eliminated.

State2: in both presence and lack of presence of DG the zone feeder relay current is equal to 11.144 Kamp that shows the DG presence didn't have considerable effect on crossing current on zone feeder.

State3: in both situation of DG presence or lack of it in that situation the zone feeder relay current is 1.578 Kamp that shows the DG presence doesn't have considerable effect on crossing current of zone feeder relay and the performance time.

State4: the short connection current at considered point is $1.588 \mathrm{Kamp}$ and the zone feeder relay current is 1.104 Kamp while the DG doesn't connect to network.

State5: the short connection current at considered point is $1.254 \mathrm{Kamp}$ and the zone feeder relay current is $1.254 \mathrm{Kamp}$ that shows in presence of DG the cut command will be issued 4 cycle later.

State6: when the single phase error occurred in zone feeder relay, any current doesn't flow from the DG units. Therefore the E.F can't be used. For these kind of error the earth error voltage protection is used.

At error occurrence in adjacent feeders the voltage turned to zero that may cause the voltage relay performance. The reasonable setting can prevent this occurrence. If each one of take placed errors were crossing, 
the renewed relay performances will be notable. With renewed situations of DG unit and its synchronic situation with network, needs the stability and renewed connection setting studies.

\section{Conclusion}

It was determined that in state 6 the lack of justifying occurred between the protection systems and it is related to the protective relays under the present situations with least changes in protective arrangement. In DG linkage protection challenges it is obvious that suggestions about the advanced protective devices is not possible. It just possible to study the directed current extra relays therefore. Decision about the protection philosophy and system justifying in scattered production unit's entrance and the number of junction units. Therefore the needed studies for the scattered unit entrance to the system in each situation as an especial state needs the study and decision making about the protection systems.

\section{Resources}

[1]. Haqifam. M. "the maximum capacity of scattered resources determination for the feus justifying in distributed network" $22^{\text {nd }}$ of international power conference, Iran, 1386 (in Persian).

[2]. BBC, protection Relay Catalog, 1996

[3]. T.Tran-Quoc, C.Andrieu, N.Hadjsaid, "Technical impacts of small distributed generation units on LV networks", IEEE Powr Engineering Society General Meeting, 2003

[4]. J. Dolezal, P.Santarius, J.Tlusty, v. valouch, F.Vybiralik, " The effects of dispersed generation on power quality in distribution system", CIGRE/IEEE Int. symp. on Quality and Security of Electric Power Delivery Systems,pp.204-207, oct.2005

[5]. F. M. Gatta, F. Iiiceto, S. Lauria, P. Masato, "Modelling and computer simulation networks, Measures to prevent disconnection during system disturbances", IEEE PowerTech Conf., June 2006, Italy. 